
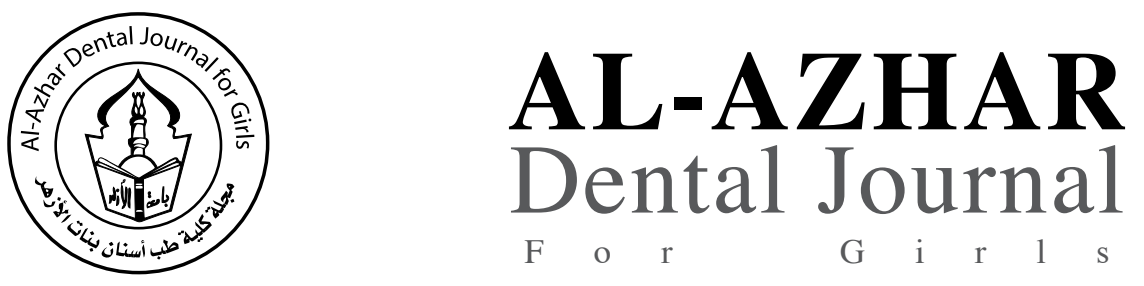

The Official Publication of The Faculty of Dental Medicine For Girls, Al-Azhar University Cairo, Egypt.

ADJ-for Grils, Vol. 4, No. 1, January (2017) — PP. 71:78

\title{
Evaluation of Low Intensity Laser on the Rate of Orthodontic Tooth Movement
}

\author{
Rabab A. El-Hosieny ${ }^{(1)}$, Samir A. Ibrahim ${ }^{(2)}$, Fatma A. Abd El-Samad ${ }^{(3)}$ and Hend S. Hafez ${ }^{(4)}$
}

Codex : 10/1701

dentaljournal.forgirls@yahoo.com

Paper extracted from Master

Thesis in Orthodontics entitled"

Evaluation of Low Intensity

Laser on the Rate of Orthodontic

Tooth Movement".

\section{KEYWORDS}

LILT, canine retraction, accelerated tooth movement.

\begin{abstract}
Objective: to evaluate the effect of low intensity laser therapy on the rate of orthodontic tooth movement in adolescent females. Materials and Methods: A sample of 10 patients with an age range of 14-18 years requiring extraction of first premolars was selected for this study. A randomized split-mouth study design was used. A nickeltitanium closed-coil spring was used for canine retraction on mini-implants. The study side received low intensity laser therapy (LILT) from a semiconductor (aluminium gallium arsenide) diode laser with a wavelength of $910 \mathrm{~nm}$. The laser regimen was applied on days $0,3,7$, and 14 in the first month, and thereafter on every 15 th day until complete canine retraction was achieved on both sides. Tooth movement was measured on progress models every 60 days. Results: The rate of canine retraction showed statistical significant higher rate on study side than that on the control side. Conclusions: The results revealed that, the ratio of the rate of orthodontic tooth movement of the laser side to the control side was (1.09); throughout the study period which was 6 months.
\end{abstract}

\section{INTRODUCTION}

One of the main problems during orthodontic treatment is the treatment time that may increase periodontal damage, enamel demineralization and root resorption. Prolonged treatment duration can also cause patient burnout and lack of patient co-operation. The reduction of orthodontic treatment time is a primary aim for all orthodontists. Low level laser therapy may be a solution for this problem as a non invasive method of accelerating tooth movement in a physiological manner. However the available evidence is still inconclusive.

1. BDS 2008 Cairo University. Assistant researcher, Department of Orthodontics and Pediatric Dentistry, National Research Center.

2. Professor of Orthodontics and Head of Orthodontic Department, Faculty of Dental Medicine for Girls, Al-Azhar University Girls’ Branch.

3. Assistant Professor, orthodontic department -faculty of dental medicine for girls Al-zhar university

4. Assistant Professor of orthodontics, Department of Orthodontics and Pediatric Dentistry, National Research Center. 
Low level laser therapy (LLLT) proved that it had a bio-stimulatory effect on bone formation by the stimulation of receptor activator of the nuclear factor-kB (RANK) / RANK ligand (RANKL) / osteoprotegerin (OPG) system which are essential and sufficient for osteoclastogenesis ${ }^{(1)}$.

So, this bio-stimulatory effect of LLLT on bone turn over guided many orthodonticts to study its effect on the rate of orthodontic tooth movement as an alternative non invasive method in accelerating tooth movement.

In 1997, the primary study in the field of low laser level therapy was regeneration of mid-palatal suture in mice has been studied using low level laser therapy (Ga-Al-As with an output of $100 \mathrm{mw}$ for 3-10 minutes per day for 7 days). The results showed that lasers can increase the speed of regeneration of bone in the mid-palatal suture and the rate is related to dose, time and frequency of the rays ${ }^{(2)}$.

In (2004) the first study on human in this field carried out, the study investigated the effect of lowintensity laser therapy on orthodontic tooth movement. The authors showed that the irradiated canines were retracted at a rate of $34 \%$ greater than the control canines over a period of 60 days ${ }^{(3)}$.

The majority of published research outcomes indicate an increase in the rate of tooth movement after laser therapy compared to controls; however, there are other reports show no difference after laser application, while other investigations concludes that lasers negatively affect tooth velocity, so according to these findings the effect of low level laser on accelerating orthodontic tooth movement is a contra versial subject ${ }^{(4)}$.

In a recent systematic review, the authors indicated that low level laser therapy was unable to accelerate orthodontic tooth movement due to method heterogeneity in LLLT application in the previous studies ${ }^{(4)}$.
Thus, the aims of this study were to evaluate the effect of low-intensity laser therapy on the rate of orthodontic tooth movement during canine retraction.

\section{SUBJECTS AND METHODS}

Study population: This study was performed on 10 subjects with an age ranged from 14 to 18

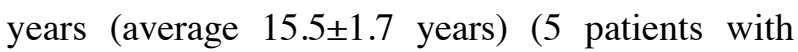
class II division 1 malocclusion and the other 5 patients with bimaxillary protrusion). The subjects were selected and treated at the out-patient clinic of the Orthodontic Department, Faculty of Dental Medicine for girls, Al-Azhar University Girls' Branch.The criteria for subject selection were as following:

1. Patients in need to extract both maxillary first premolars.

2. Patients exhibiting Class II division I or with bi-maxillary protrusion.

3. Full retraction of the maxillary canines and maximum anchorage needed as a part of the orthodontic treatment plan.

4. All permanent teeth other than the third molars were present and fully erupted in both arches.

5. Patients should have good oral hygiene.

6. Medically compromised patients were excluded.

7. Patients under medical treatment that affect the rate of orthodontic tooth movement were excluded.

\section{B. Methods:}

The aim and methods of the study was explained to the patients and consents were signed by all participants before being enrolled in this study. Routine orthodontic records had been taken for each patient before start of orthodontic treatment: 
1. Exta-oral photographs.

2. Inta-oral photographs.

3. Orthodontic study model.

4. Digital Panoramic Radiogragh.

5. Lateral Cephalometric Radiograph.

The study was designed as randomly assigned incomplete block split-mouth design was used to prevent inter-individual biologic variation ${ }^{(5)}$. A sample of 10 patients was randomly selected for the study side (laser side) and control side using Microsoft Office Excel 2007.

Both the maxillary right and the left first premolars were extracted in each patient, and then a period of 16-20 weeks was maintained after extraction and before canine retraction. Concurrently, it ensured that the quality of bone around the canine roots was of similar density ${ }^{(6)}$.

Immediately after extraction, leveling and alignment of maxillary teeth were done by placement of $0.022 \times 0.028$-inch pre-adjusted brackets (Mini 2000. Oramco Corp, Caifornia, USA) and successive arch wires were progressively placed until 0.016 x 0.0022 -inch stainless-steel wires (Acti-4S Stainless Steel Archwire. Modern Orthodontics LLC, California, USA).

For canine retraction, temporary anchorage device (Abso Anchor Temporary anchorage device, Korea) with $8 \mathrm{~mm}$ in long, and $1.6 \mathrm{~mm}$ in diameter and the thread forming were manually inserted into the buccal cortical bone between the maxillary first molar and maxillary second premolar on both sides. The distal wing of the canine bracket was fixed using 0.009-inch wire ligature wire to the arch wire to avoid rotation of canine during retraction. A 5mm super elastic Nickel-Titanium coil spring (Vector Tas NiTi coil sprig. Ormco Corp, California, USA) delivered a constant force of 200 $\mathrm{g}$ which was adjusted by force gauge (VST Corp, China). One end of the coil spring was attached to the mini-implant head, the other end was attached to the graduated post (Vecror Tas Post. Ormco Corp, California, USA) placed anterior to canine.

At every appointment, the appliance in every subject was assessed for damage as a quality-control measure; as a bracket, arch wire or a spring involved in canine retraction showed any damage, or if the patient did not follow low level laser application regimens patient was excluded from the study.

Also, at every appointment mini-implants were checked for looseness and if it found immediate reinsertion of mini-implant was carried out in a higher position.

\section{Low level laser irradiation:}

Low-intensity laser therapy was started on the selected experimental side on the same day as placement of the coil spring, using Gallium Aluminum Arsenide (Ga-Al-As) semiconductor diode laser (Pocket Laser. Orotig company, Italy) emitting infrared radiation of wavelength 910 $\mathrm{nm}$ and power output $0.2 \mathrm{~W}$ in a continuous noncontact wave mode. The laser beam was delivered using a round $1 \mathrm{~cm}$ diameter head conductor held perpendicular to mucosa. The laser device was checked for accuracy of power output using power meter, at the start of this study; to ensure the accuracy of the laser device.

The study sides were irradiated from the buccal and palatal sides for 20 seconds for each over an area of $0.7857 \mathrm{~cm}^{2}$.

The laser regimen was applied on days $0,3,7$ and 14 in the first month. Thereafter, irradiations were done on every 15 th day until complete canine retraction on both sides, which was over an average period of six months. 
The application dose (the amount of energy applied at any one given treatment) was $4 \mathrm{~J}$ on study side with energy density of $5.09 \mathrm{~J} / \mathrm{cm}^{2}$ and power density of $0.25 \mathrm{~W} / \mathrm{cm}^{2}$ per side ${ }^{(3)}$.

Precautions were taken before LLL application procedure where both the patient and the operator used appropriate protective glasses specific for the wavelength used according to the safety rules. It is worth mentioning that all LLL irradiations were done by the same operator, to prevent intraoperator variations.

Each subject in this study received an average of 11 - 15 times of laser application sessions along six months of the study time, with a total dose ranged between $44-60 \mathrm{~J}$ (on buccal and on palatal sides) and total energy dose ranged between $88-120 \mathrm{~J}$ (buccal + palatal).

\section{Measurement of the rate of canine retraction:}

Four models were made for each patient. On the models, the following reference points were marked using 0.7-mm marker $^{(7)}$ :

1- The incisive papilla.

2- The medial end of the left third ruga.

3- The medial end of the right third ruga.

4- Marked on the median raphe opposite to point (2).

5- Marked on the median raphe opposite to point (3).

6- Marked the cusp tip of the left canine.

7- Marked the cusp tip of the right canine.

8- The end of medial palatine raphe.

The models were then scanned from an occlusal perspective using digital scanner (Xerox work centre 7655.Hewlett-Packard Company, California, U.S.A). Then Adobe Photoshop CS3 version 9.0 was utilized after scanning to measure amount of canine movement on right and left sides.

These distances were recorded at T0 (after completion of alignment and leveling: day 1 of canine retraction), T1 (at the end of 2 months of canine retraction), T2 (at the end of 4 months of canine retraction) and T3 (at the end of 6 months of canine retraction).

The difference between the canine positions recorded at three intervals; first interval (T0-T1), second interval (T1-T2) and third interval (T2-T3). The results were subjected to statistical analysis.

\section{RESULTS}

Table (1) shows the descriptive statistics and comparison (using one way analysis of difference ANOVA test) of the mean monthly rate of the canine displacement in different intervals within the same group. In the laser side, the monthly rate traveled by the canine in the second interval $(1.39 \pm 0.084 \mathrm{~mm})$ was significantly greater than the rate $(0.99 \pm 0.16 \mathrm{~mm})$ traveled by the canine in the first interval, while a significantly lower daily rate $(0.66 \pm 0.0048)$ was recorded in the third interval $(\mathrm{p}<0.0001)$.

Table (2) shows the descriptive statistics and comparison of the daily rate of the canine displacement in different intervals (each interval 60 days) and throughout the study (overall 180 days). In the first interval, a daily rate of $(0.033 \pm 0.008$ $\mathrm{mm}$ ) was traveled by the canine in the laser side which was not significantly different than the rate $(0.036 \pm 0.007 \mathrm{~mm})$ traveled by the canine in the non-laser side, $(\mathrm{p}=0.7695)$.

Table (3) shows the descriptive statistics and comparison (using one way analysis of difference ANOVA test) of the mean daily rate of the canine displacement in different intervals within the same group. In the laser side, the daily rate was traveled by the canine in the second interval $(0.046 \pm 0.0028$ $\mathrm{mm}$ ) which was significantly greater than the rate $(0.033 \pm 0.008 \mathrm{~mm})$ traveled by the canine in the first interval, while a significantly lower daily rate $(0.022 \pm 0.0016)$ was reorded in the third interval $(\mathrm{p}<0.0001)$, 
Table (1): Comparison of the monthly rate of canine displacement in different intervals within the same group, and significance of the different between intervals using ANOVA test.

\begin{tabular}{|c|c|c|c|c|c|c|c|}
\hline Group & Interval & Min. & Max. & $\operatorname{Mean}(\mathbf{m m})$ & S.D. & $F$-value & $\mathbf{P}$ \\
\hline \multirow{3}{*}{ Laser } & First & 0.36 & 1.93 & $0.99^{\mathrm{b}}$ & 0.16 & \multirow{3}{*}{16.532} & \multirow{3}{*}{$<0.0001 *$} \\
\hline & Second & 0.57 & 2.1 & $1.39^{\mathrm{a}}$ & 0.084 & & \\
\hline & Third & 0 & 0.69 & $0.66^{\mathrm{c}}$ & 0.048 & & \\
\hline \multirow{3}{*}{ Non- laser } & first & 0.61 & 1.7 & $1.08^{\mathrm{b}}$ & 0.18 & \multirow{3}{*}{18.61} & \multirow{3}{*}{$<0.0001 *$} \\
\hline & Second & 0.75 & 1.65 & $0.6^{\mathrm{a}}$ & 0.075 & & \\
\hline & Third & 0 & 0.98 & $0.53^{\mathrm{c}}$ & 0.045 & & \\
\hline
\end{tabular}

$N=10$.

t: Unpaired t-test.

* Significant, $n s=$ non significant at $p \leq 0.05$

Table (2): Comparison of the daily rate of canine displacement in both sides at different intervals and throughout the study, and significance of the different between both groups using unpaired test.

\begin{tabular}{|c|c|c|c|c|c|c|c|}
\hline Interval & Group & Min. & Max. & $\operatorname{Mean}(\mathbf{m m})$ & S.D. & $t$-value & $\mathbf{P}$ \\
\hline \multirow{2}{*}{ First } & Laser & 0.012 & 0.065 & 0.033 & 0.008 & \multirow{2}{*}{0.2975} & \multirow{2}{*}{$0.7695^{\mathrm{ns}}$} \\
\hline & Non-laser & 0.021 & 0.057 & 0.036 & 0.007 & & \\
\hline \multirow{2}{*}{ Second } & Laser & 0.019 & 0.07 & 0.046 & 0.0028 & \multirow{2}{*}{2.5274} & \multirow{2}{*}{$0.0211 *$} \\
\hline & Non-laser & 0.025 & 0.055 & 0.039 & 0.0025 & & \\
\hline \multirow{2}{*}{ Third } & Laser & 0.000 & 0.046 & 0.022 & 0.0016 & \multirow{2}{*}{2.8837} & \multirow{2}{*}{$0.0099 *$} \\
\hline & Non-laser & 0.000 & 0.033 & 0.018 & 0.0015 & & \\
\hline \multirow{2}{*}{ Overall } & Laser & 0.029 & 0.036 & 0.033 & 0.0011 & \multirow{2}{*}{2.7735} & \multirow{2}{*}{$0.0125^{*}$} \\
\hline & Non-laser & 0.022 & 0.037 & 0.031 & 0.0003 & & \\
\hline
\end{tabular}

$N=10$.

* Significant at $p \leq 0.05$

Table (3): Comparison of the daily rate of canine displacement in different intervals within the same group, and significance of the different between intervals using ANOVA test.

\begin{tabular}{|c|c|c|c|c|c|c|c|}
\hline Group & Interval & Min. & Max. & $\operatorname{Mean}(\mathbf{m m})$ & S.D. & $F$-value & $\mathbf{P}$ \\
\hline \multirow{3}{*}{ Laser } & First & 0.012 & 0.065 & $0.033^{\mathrm{b}}$ & 0.008 & \multirow{3}{*}{14.385} & \multirow{3}{*}{$<0.0001 *$} \\
\hline & Second & 0.019 & 0.07 & $0.046^{\mathrm{a}}$ & 0.0028 & & \\
\hline & Third & 0.000 & 0.046 & $0.022^{\mathrm{c}}$ & 0.0016 & & \\
\hline \multirow{3}{*}{ Non- laser } & First & 0.021 & 0.057 & $0.036^{\mathrm{b}}$ & 0.007 & \multirow{3}{*}{17.913} & \multirow{3}{*}{$<0.0001 *$} \\
\hline & Second & 0.025 & 0.055 & $0.039^{\mathrm{a}}$ & 0.0025 & & \\
\hline & Third & 0.000 & 0.033 & $0.018^{\mathrm{c}}$ & 0.0015 & & \\
\hline
\end{tabular}

$N=10$.

$t$ : Unpaired t-test.

* Significant, $n s=$ non-significant at $p \leq 0.05$ 


\section{DISCUSSION}

Many studies reported that laser wave length and energy density are the most important factors determining the tissue response to LILT $^{(8)}$.

Another factor that may interpret the results of LLL bio-stimulatory effect -in different articles- is interspecies bone density differences and in different sites of the same species; this finding may explain the wide variety in results between animal and human studies result on bone ${ }^{(9)}$, so this discussion will include human studies only.

In the present study, semiconductor diode laser was used with a wavelength of $910 \mathrm{~nm}$, in a continuous wave mode, with energy density of $5.09 \mathrm{~J} / \mathrm{cm}^{2}$, to investigate the effect of low level laser on the rate of orthodontic tooth movement, because the results of previous studies had indicated a significant biostimulatory effect on bone metabolism around this dosage ${ }^{(3)}$.

Multiple applications with LILT with average of 17 exposures were used in the present study, as other studies reported that multiple applications of LLL seem to be superior to a single exposure; when comparing the cumulative dosages bio-stimulatory effect between the two modes of application ${ }^{(10)}$.

The results of the present study concluded that low level laser had stimulatory effect on acceleration of orthodontic tooth movement agreed with the findings which were reported by many human studies ${ }^{3}$, $11,12,13,14,15,16,17,18,19)$ and disagreed with other studies which showed no effect on tooth movement ${ }^{(20,21,22)}$. This controversial results in the previous studies may be due to the different energy densities they used; which mentioned in Arndt-Schulz law; who stated that low doses have stimulatory and high dosages have inhibitory effects ${ }^{(23)}$ or may be due to the longer wavelengths they used ${ }^{(8)}$.

On evaluating the rate of orthodontic tooth movement in the present study, the results showed statistically significant increase in the ratio of the rate of tooth movement in the study group compared to the control group by 1.09 throughout the six months of the study.

Similar results were found in other studies but with a higher rate. In a study used $780 \mathrm{~nm}$ laser, they found acceleration in the ratio of the rate of canine retraction on the study group by 1.3 over a period of 60 days, on the other hand in the present study there was no statistically significant result in similar period; this may be due to that the accumulative effect of longer wave length laser $910 \mathrm{~nm}$ occurs at more number of applications ${ }^{(3)}$.

In the first interval of the present study (T0-T1), there was no statistical significant difference between the rate of orthodontic tooth movement in the laser group and control group. This finding is in agreement with another study used nearly the same wave length of $904 \mathrm{~nm}$ with energy density of at 4.2 $\mathrm{J} / \mathrm{cm}^{2}$, after 63 days from the start of activation ${ }^{(21)}$. This result may be due to that the accumulative effect of LLLT did not yet occur that may be affected by longer laser wave length used ${ }^{(8,10)}$.

In a randomized clinical study ${ }^{(13)}$, the author followed the recommendation of another study ${ }^{(3)}$; of using the following regimen of laser application 0 , $3,7,14$ and 28; as they mentioned that "An activation after a period shorter than 30 days would not only maintain spring tension values closer to the initial value of $150 \mathrm{~g}$ but probably also decrease the necessary treatment time even more". The results found increase in the ratio of the rate of canine retraction in study group to control group by 1.44 after six months.

The same finding was mentioned in other four different studies ${ }^{(12,15,18,19)}$. All of previously mentioned studies reported a higher ratio of the rate of canine retraction in the study group than in the present study; through their different study periods (4 months, 1 month, 3 months and 1 month respectively). This is may be due to the shorter wave length laser they used $(780 \mathrm{~nm}, 808 \mathrm{~nm}, 810 \mathrm{~nm}$ and $670 \mathrm{~nm}$ respectively). 
The highest rate of acceleration was found in a clinical trial ${ }^{(11)}$, and it was (1.98-fold) in the lased group after 6 months, this may be due to the increased irradiation frequency of 4 times per month compared with 4 times per month in the first month and 2 times per month in subsequent months in the present study and other studies. Also may be due to the short wavelength laser they used $(809 \mathrm{~nm})$.

In contrary to our result, a randomized double blinded clinical study used (Ga-Al-As) with wavelength of $860 \mathrm{~nm}$ and energy density of $\left(25 \mathrm{~J} / \mathrm{cm}^{2}\right)$ for 4 months and their results showed no statistical significant between laser group and control group ${ }^{(20)}$. This may be due to the high energy density they used; which is against Arndt-Schulz law of bio-stimulatory doses ${ }^{(23)}$.

The same finding was also reported by another study ${ }^{(17)}$, in which a short wavelength diode laser of $810 \mathrm{~nm}$ was used with high energy density of $\left(21.4 \mathrm{~J} / \mathrm{cm}^{2}\right)$, and there was no statistically significant effect of LILT after 56 day of follow up.

Also in a disagreement with the present study, a more recent study ${ }^{(22)}$; occupying Gl-Al-As semiconducting diode laser with long wavelength of 940 $\mathrm{nm}$ and a high energy density of $20 \mathrm{~J} / \mathrm{cm}^{2}$, and the author found that no statistical significant difference between the laser group and control group.

Despite another clinical study ${ }^{(14)}$; authors did not follow Arndt-Schulz law of bio-stimulatory doses as they used high energy density of $24 \mathrm{~J} / \mathrm{cm}^{2}$, they investigate increase in the rate of canine retraction by $30 \%$ after 4.5 month of exposure to LILT of $810 \mathrm{~nm}$ wave length.

\section{CONCLUSION}

1- Low intensity laser therapy is able in some way to cause acceleration of orthodontic tooth movement, but further studies should be conducted to determine the most effective wave length and dose for acceleration of orthodontic tooth movement.

2- Wave length of laser seems to have the high influence on LILT bio-stimulatory effect, in conjugation with energy density and number of applications.

\section{REFERENCES}

1- Saito S, Shimizu N. Stimulatory effects of low-power laser irradiation on bone regeneration in midpalatal suture during expansion in the rat. Am J Orthod Dentofacial Orthop. 1997;111:525-32.

2- Goyal M., Makkar S., Pasricha S. Low Level Laser Therapy in Dentistry. Int J Las Dent. 2013;3:82-8.

3- Cruz D., Kohara E., Ribeiro M., Wetter N. Effects of LowIntensity Laser Therapy on the Orthodontic Movement Velocity of Human Teeth : A Preliminary Study. Lasers Surg Med. 2004;35:117-20.

4- Long H. et al. Interventions for accelerating orthodontic tooth movement: A systematic review. Angle Orthodontist. 2013;83:164-71.

5- Antczak-Boukoms AA, Tulloch JF, Berkey CS. Splitmouth andcross-over designs in dental research. J Clin Periodontol. 1990;17:446-53.

6- Häsler R., Schmid G., Ingervall B., Gebauer U. A clinical comparison of the rate of maxillary canine retraction into healed and recent extraction sites-a pilot study. Eur J Orthod. 1997;19:711-9.

7- Ziegler P., Ingervall B. A clinical study of maxillary canine retraction with a retraction spring and with sliding mechanics. Am J Orthod Dentofac Orthop. 1989;95:99-106.

8- Baxter G, Diamantopoulos C. Therapeutic Lasers: Theory and Practice. 1st ed. New York: Elsevier Health Sciences; 1995. p. 1-8.

9- Aerssens J., Boonen S., Lowet G., Dequeker J. Interspecies differences in bone composition, density, and quality: potential implications for in vivo bone research. J Endocrinology. 1998;139:663-70.

10- Ng G., Fung D., Leung M., Guo X. Comparison of single and multiple applications of GaAlAs laser on rat medial collateral ligament repair. Lasers Surg Med. 2004; 34:285-9. 
11- Youssef M., Ashkar S., Hamade E., Gutknecht N., Lampert F., Mir M. The effect of low-level laser therapy during orthodontic movement: a preliminary study. Lasers Med Sci. 2008;23:27-33.

12- Sousa M., Scanavini M., Sannomiya E., Velasco L., Angelieri F. Influence of low-level laser on the speed of orthodontic movement. Photomed Laser Surg. 2011; 29:191-6.

13- Mahmoud N. The effect of low level laser therapy the rate of orthodontic tooth movement, prostaglandin $\mathrm{E}_{2}$ and pain level. Master Thesis. University of Alexandria; 2011.

14- Doshi-Mehta G., Bhad-Patil W. Efficacy of low-intensity laser therapy in reducing treatment time and orthodontic pain: A clinical investigation. Am J Orthod Dentofac Orthop. 2012;141,289-97.

15- Genc G., Kocadereli I., Tasar F., Kilinc K., El S., Sarkarati B. Effect of low-level laser therapy (LLLT) on orthodontic tooth movement. Lasers Med Sci. 2013;28:41-7.

16- Kau C., Kantarci A., Shaughnessy T., Vachiramon A., Santiwong P., de la Fuente A., Skrenes D., Ma D., Brawn P. Photobiomodulation accelerates orthodontic alignment in the early phase of treatment. Prog orthod. 2013;14:30-9.

17- Heravi F., Moradi A., Ahrari F. The effect of low level laser therapy on the rate of tooth movement and pain perception during canine retraction. OHDM. 2014;13:183-8.

18- Garg N., Singh G., Kannan S., Rai D., Kaul A., Gupta A. effect of $810 \mathrm{~nm}$ diode laser therapy on the rate of extraction space closure. J Ind Orthod Society. 2014;48:143-8.

19- Domínguez A., Gómez C., Palma J. Effects of low-level laser therapy on orthodontics: rate of tooth movement, pain, and release of RANKL and OPG in GCF. Lasers Med Sci. 2015;30:915-23.

20- Limpanichkul W., Godfrey K., Srisuk N., Rattanayatikul C. Effects of Low Level Laser Therapy on the rate of orthodontic tooth movement. Orthod Craniofacial Res. 2006;9:38-43.

21- Kansal A., Kittur N., Kumbhojkar V., Keluskar K., Dahiya P. Effects of low-intensity laser therapy on the rate of orthodontic tooth movement: A clinical trial. Dent Res J. 2014;11:481-8.

22- Awad M. The effect of $940 \mathrm{~nm}$ laser therapy on the rate of orthodontic tooth movement, prostaglandin $\mathrm{E}_{2}$ and pain level (A Randomized Clinical Study). Master Thesis. University of Cairo; 2015.

23- Coluzzi D. Fundamentals of dental lasers: Science and instruments. Dent Clin North Am. 2004;48:751-70. 